ORIGINAL ARTICLE

\title{
Gastric ciliated metaplasia. A study of 3406 gastrectomy specimens from dwellers of the Atlantic and the Pacific basins
}

\author{
C A Rubio, G Nesi, G C Zampi, P A de Ruiz, J Jessurun, J Jónasson, R Hojman, Z Kogan, \\ D Antonioli, M L Miller, T Hirota, T Itabashi, K Mandai, T Kitagawa, H Sugano, Y Kato, A King, \\ R Pisano, D Owen
}

See end of article for authors' affiliations

......................

Correspondence to: Dr C A Rubio,

Gastrointestinal and Liver Pathology Research Laboratory, Department of Pathology, Karolinska Institute and University Hospital, Stockholm, Sweden; Carlos.Rubio@ onkpat.ki.se

Accepted for publication 1 November 2004

\begin{abstract}
Background: Ciliated cells in gastrectomies from patients dwelling in the Pacific and Atlantic basins have been reported previously.

Aim: To compare all the results in an attempt to explain the findings.

Methods: Sections from 3406 gastrectomies were reviewed: 1966 and 1440 from the Atlantic and Pacific basins, respectively. Ciliated cells and intestinal metaplasia (IM) were recorded; IM was classified into focal or extensive IM. The total number of sections/gastrectomy was noted.

Results: In the Atlantic basin, 5\% of specimens had ciliated metaplasia (CM); it was more frequent in intestinal carcinoma (IC; 9\%) than diffuse carcinoma (DC; 3\%) or miscellaneous gastric diseases (MGD; $3 \%$ ). In the Pacific basin, the frequency of specimens with CM was $29 \%$ : it was more frequent in IC (43\%) than in DC (16\%) or MGD (10\%). The difference between the frequency of CM in specimens with IC or with $D C / M G D$ in the Atlantic and the Pacific basins was significant $(p \leqslant 0.05)$. The presence of CM was influenced by age and the extent of $I M$ in both basins, but not by sex or the number of sections investigated.

Conclusions: CM-apparently an independent microscopic marker-was significantly higher in the Pacific than in the Atlantic basin. Environmental carcinogens involved in the evolution of IM and IC seem to be implicated in gastric ciliogenesis. Carcinogens that differ in nature and/or in strength in both basins might activate the latent natural genes encoding ciliated processes in gastric cells in patients subsequently developing gastric carcinoma, more notably of intestinal type.
\end{abstract}

A lthough ciliated cells cover the oesophageal epithelium during ontogenesis, ciliated cells are not found in the normal gastric mucosa before or after birth. ${ }^{1}$ Consequently, the presence of such cells in the gastric mucosa should be regarded as a pathological finding.

"A comparative study between all the results obtained in the two basins has never been undertaken"

Before 1983, only six patients with gastric ciliated cells had been reported, and all were Japanese. Kodaira et al ( $\mathrm{T}$ Kodaira et al. Ciliated epithelium in gastric mucosa observed in chronic gastritis. An electron microscopic study. Proceedings of the Japanese Cancer Association, 33rd Annual Meeting, 1974, p184) found ciliated cells in two patients with chronic gastritis, Okuda and Ogata $^{2}$ in three patients (two with duodenal ulcers and one with a gastric adenoma), and Yamashiro and colleagues ${ }^{3}$ in one patient harbouring a carcinoma elsewhere in the stomach. The ciliated gastric cells were detected at the electron microscopical level.

In 1983, while looking at haematoxylin and eosin stained sections at high power $(\times 40)$ using a conventional microscope, we found ciliated metaplasia in six Japanese patients with gastric adenoma. ${ }^{4}$ In 1984, Stemmermann and colleagues $^{5}$ assumed that approximately $10 \%$ of the stomachs with intestinal metaplasia (IM; mainly from Japanese patients living in Hawaii) had ciliated cells. In 1986, we found that ciliated metaplasia occurred in 35\% of 137 gastrectomy specimens taken from Japanese patients living in Japan. ${ }^{6}$ In the same year, Torikata et al (C Torikata C et al. Ciliated cells in human metaplastic gastric mucus. A proposal of a new term; ciliated metaplasia. Proceedings of the XI International Congress on Electron Microscopy, 1986, Kyoto, p3549-52.) reported "numerous ciliated cells in more than 30 cases of resected specimens in the pyloric gland and only two cases in the cardiac gland" in Japanese stomachs. Four years later, Torikata et al found ciliated metaplasia in 42 of 100 consecutive resected Japanese stomachs, ${ }^{7}$ and in 1992 in 51 of 100 consecutive gastrectomies (95 with carcinoma and five with peptic ulcer). ${ }^{8}$ In 1993, among Hong-Kong Chinese, Chan et al found ciliated metaplasia in 11 of 22 gastrectomies taken for carcinoma and in five of 13 gastrectomies taken for peptic ulcer. ${ }^{9}$ Those authors ${ }^{9}$ demonstrated cilia even in the tumour cells in one of the cases.

In subsequent studies in other countries at the rim of the Pacific basin, ${ }^{10-17}$ we found a high frequency of gastrectomies with ciliated metaplasia. In contrast, investigations of populations from the Atlantic basin ${ }^{18-23}$ found a lower frequency of specimens with ciliated metaplasia. Our reports were based on results obtained at individual institutions located in the Atlantic and in the Pacific basins. However, a comparative study between all the results obtained in the two basins has never been undertaken.

The purpose of our study was to compare the frequency of gastrectomies with ciliated gastric cells between patients

Abbreviations: DC, diffuse carcinoma; EIM, extensive intestinal metaplasia; IC, intestinal carcinoma; IM, intestinal metaplasia; MGD, miscellaneous gastric diseases 
Table 1 The number of gastrectomies with ciliated metaplasia/total number of gastrectomies performed in 1966 patients dwelling at the rim of the Atlantic basin

\begin{tabular}{llllll}
\hline Location & IC & DC & Adenoma & Miscellaneous & All cases with cilia \\
\hline New York & $14 / 344(4 \%)$ & $1 / 235(0.4 \%)$ & & $2 / 48(4 \%)$ & $17 / 627(3 \%)$ \\
London & $3 / 65(5 \%)$ & $0 / 56(0 \%)$ & $4 / 56(7 \%)$ & $7 / 177(4 \%)$ \\
Reykjavik & $20 / 141(15 \%)$ & $6 / 160(4 \%)$ & & $6 / 134(4 \%)$ & $32 / 435(7 \%)$ \\
Florence & $26 / 116(22 \%)$ & $9 / 70(13 \%)$ & & $35 / 186(19 \%)$ & $1 / 205(0.5 \%)$ \\
Mexico City & $1 / 16(6 \%)$ & $0 / 12(0 \%)$ & & $0 / 177(0 \%)$ & $1 / 21(5 \%)$ \\
Buenos Aires & $2 / 76(3 \%)$ & $1 / 69(1 \%)$ & & $2 / 53(4 \%)$ & $7 / 117(6 \%)$ \\
Boston & $0 / 11(0 \%)$ & $0 / 10(0 \%)$ & $1 * / 1$ & - & $105 / 1966(5 \%)$ \\
Stockholm & $4 / 47(8 \%)$ & $1 / 36(3 \%)$ & $1 * / 1$ & $16 / 502(3 \%)$ & \\
Total & $71 / 816(9 \%)$ & $18 / 648(3 \%)$ & & \\
\hline *Adenoma without invasion. & & & \\
DC, diffuse carcinoma; IC, intestinal carcinoma. & &
\end{tabular}

dwelling at the rim of the Pacific ${ }^{10-17}$ and Atlantic ${ }^{18-23}$ basins. From that comparison, conclusions were drawn regarding the possible influence of environmental, ethnic, and genetic factors in the development of gastric ciliated metaplasia.

\section{MATERIALS AND METHODS}

Filed haematoxylin and eosin stained sections from 3406 gastrectomy specimens from dwellers of the Pacific $(\mathrm{n}=1440)$ and the Atlantic $(\mathrm{n}=1966)$ basins were reviewed. Some of the results of those studies have been reported elsewhere. ${ }^{10-23}$

A review of that material, which originated from between 1981 and 1999, was carried out at the various hospitals by one of the authors (CAR). Randomly selected cases were discussed with host pathologists at the respective hospitals.

To detect glands with ciliated metaplasia, the basal aspect of gastric pyloric glands was carefully studied using $\times 20$ or $\times 40$ objective magnifications. In glands suspected to have ciliated metaplasia, sections were observed under oil immersion $(\times 100$ magnification $)$.

The occurrence of IM was investigated at low power $(\times 4$ objective). Specimens with IM were classified into those with "spotty" IM (sections having one or more minor glandular groups with IM in one or more sections), and those with extensive IM (EIM; sections showing a continuous segment of IM occupying one or more entire low power fields/section in one or more sections ${ }^{24}$ ).

\section{Statistical analysis}

The Wilcoxon non-parametric test and ANOVA analysis were performed using StatView Version 4.5 software (Abacus Concepts, Berkley, California, USA). Significance was defined as $\mathrm{p}<0.05$.

\section{RESULTS}

Filed sections from 3406 gastrectomy specimens were investigated.

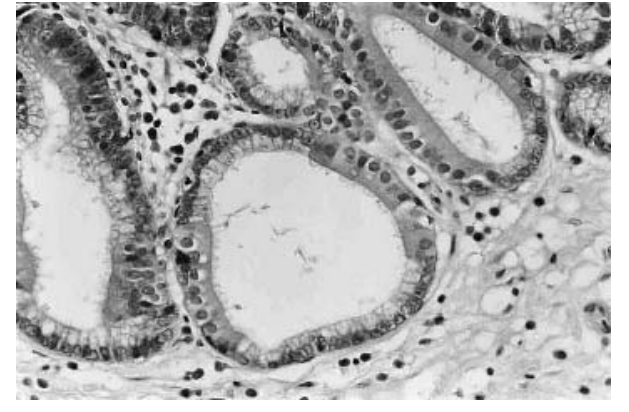

Figure 1 A group of pyloric gastric glands with ciliated metaplasia (haematoxylin and eosin stain; original magnification, $\times 25$ ).

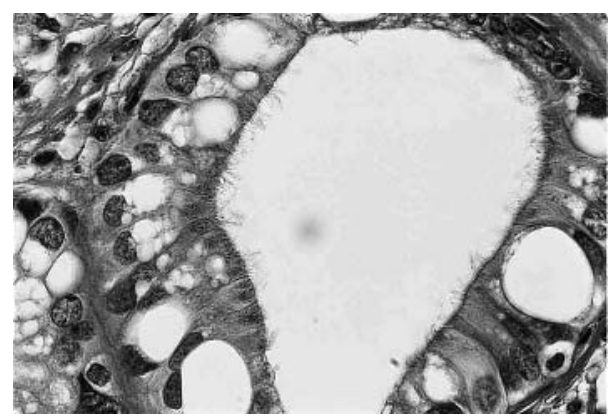

Figure 2 A closer view of a gastric gland to demonstrate both ciliated metaplasia and intestinal metaplasia (haematoxylin and eosin stain; original magnification, $\times 50$ ).

Of the 1966 specimens reviewed in the Atlantic basin (table 1), $816(41 \%)$ had carcinoma of intestinal type (IC), $648(33 \%)$ had carcinoma of diffuse type (DC), one was an

Table 2 The number of gastrectomies with ciliated metaplasia/total number of gastrectomies performed in 1440 patients dwelling at the rim of the Pacific basin

\begin{tabular}{|c|c|c|c|c|c|}
\hline Location & IC & DC & Adenoma & Miscellaneous & All gastrectomies with cilia \\
\hline Tokyo & $72 / 181(40 \%)$ & $29 / 166(18 \%)$ & $37 / 87(43 \%)$ & $5 / 35(14 \%)$ & $143 / 469(30 \%)$ \\
\hline Matsuyama & $87 / 168(52 \%)$ & $13 / 73(18 \%)$ & & - & $100 / 241(41 \%)$ \\
\hline New Zealand, Polynesians & $2 / 9(22 \%)$ & $4 / 12(33 \%)$ & & $7 / 46(15 \%)$ & $13 / 67(19 \%)$ \\
\hline New Zealand, whites & $14 / 47(30 \%)$ & $5 / 15(33 \%)$ & & $2 / 46(4 \%)$ & $21 / 108(19 \%)$ \\
\hline Honolulu, Asians & $38 / 60(63 \%)$ & $4 / 29(14 \%)$ & & $10 / 40(25 \%)$ & $52 / 129(40 \%)$ \\
\hline Honolulu, whites & $11 / 40(28 \%)$ & $1 / 14(7 \%)$ & & $2 / 11(18 \%)$ & $14 / 65(22 \%)$ \\
\hline Vancouver & $16 / 45(36 \%)$ & $5 / 56(9 \%)$ & & $7 / 140(5 \%)$ & $28 / 241(12 \%)$ \\
\hline Santiago & $36 / 64(67 \%)$ & $4 / 45(9 \%)$ & & $0 / 11(0 \%)$ & $40 / 120(33 \%)$ \\
\hline Total & $276 / 614(45 \%)$ & $65 / 410(16 \%)$ & $37 / 87(43 \%)$ & $33 / 329(10.0 \%)$ & $411 / 1440(29 \%)$ \\
\hline
\end{tabular}

DC, diffuse carcinoma; IC, intestinal carcinoma. 
adenoma $(0.05 \%)$ and the remaining 502 specimens (26\%) had miscellaneous non-neoplastic gastric diseases (MGD).

Of the 1440 specimens reviewed in the Pacific basin (table 2), 614 (43\%) had IC, 410 (28\%) DC, 87 (6\%) adenoma, and the remaining $329(23 \%)$ had MGD. The difference between the proportions of IC, DC, and MGD between the two basins was non-significant $(\mathrm{p}=0.7)$.

\section{Localisation of the ciliated gastric cells}

Ciliated metaplastic cells (figs 1-3) were found in the basal segments of the pyloric gastric glands, usually from the antrum, whose superficial parts had undergone IM. Ciliated metaplastic cells also occurred in the cardia and the corpusin areas with pseudopyloric metaplasia in specimens with widely distributed EIM-and in dilated dysplastic glands in gastric adenomas.

\section{Frequency of ciliated metaplasia}

The Atlantic basin

The mean frequency of ciliated metaplasia in the Atlantic basin was 5\% (table 1). Variations in the proportion of specimens with ciliated metaplasia were found depending upon the type of lesion present in the specimens: 9\% for gastrectomies with IC and 3\% for those with DC and MGD. In seven of the eight cities investigated in the Atlantic basin the frequency of specimens with ciliated metaplasia was $7 \%$ or lower (table 1). Table 1 also shows that the frequency of ciliated metaplasia in gastrectomies with IC varied between the different cities of the Atlantic basin, from 22\% in Florence to $0 \%$ in Boston. In gastrectomies harbouring $\mathrm{DC}$, the frequency of ciliated metaplasia also varied in the different cities, from $13 \%$ in Florence to $0 \%$ in New York, London, Mexico City, and Boston. In MGD the frequency varied from $7 \%$ in London to $0 \%$ in Mexico City.

\section{The Pacific basin}

Table 2 shows that the mean frequency of ciliated metaplasia in the Pacific basin was $29 \%$. Variations in the number of positive specimens were found depending upon the type of lesion present in the specimen: $45 \%$ for gastrectomies with IC, $16 \%$ for those with DC, $43 \%$ for those with adenoma, and $10 \%$ for those with MGD. In seven of the eight cities investigated in the Pacific basin the frequency of gastrectomies with ciliated metaplasia was $19 \%$ or higher. Table 2 also shows that in the Pacific basin the frequency of ciliated metaplasia in specimens with IC varied from $67 \%$ in Santiago de Chile to $22 \%$ in New Zealand (Polynesians). In gastrectomies harbouring a DC, the frequency of ciliated metaplasia varied from 33\% in New Zealand (both Polynesians and whites) to $7 \%$ in Honolulu (whites). In MGD, the frequency varied from $25 \%$ in Honolulu (Asians) to $0 \%$ in Santiago de Chile.

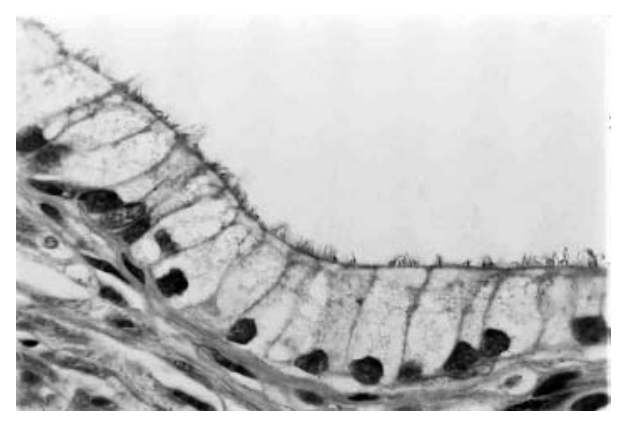

Figure 3 Detail of pyloric gland with ciliated metaplasia (Grimelius stain; original magnification, $\times 100$ ).
The difference in frequency of specimens with ciliated metaplasia having IC or DC/MGD was significant ( $p<0.05$ ). The difference was also significant between the two basins $(\mathrm{p}<0.05)$.

\section{Age and ciliated metaplasia}

In the Atlantic basin, 74\% of the 105 gastrectomies with ciliated metaplasia were performed in elderly patients $(\geqslant 60$ years; table 3). In the Pacific basin, $83 \%$ of the 411 gastrectomies with ciliated metaplasia were carried out in elderly patients (table 4). The difference between the occurrences of ciliated metaplasia among the elderly in individual basins was significant $(\mathrm{p}<0.05)$.

\section{Sex and ciliated metaplasia}

In the Atlantic population, the highest percentage of men with ciliated metaplasia was found in New York (72\%) and the lowest in Florence (57\%). In the Pacific population, the highest percentage of men with ciliated metaplasia was found in Matsuyama (77\%) and the lowest in New Zealand (whites), namely $54 \%$. No difference in the percentage of men with ciliated metaplasia was found between the Atlantic and Pacific populations analysed $(\mathrm{p}=0.6)$.

Men undergoing surgery for IC (where the proportion of cases with ciliated metaplasia was the highest) accounted for $76.7 \%$ of the gastrectomies performed in Matsuyama and for $75 \%$ of those performed in New York. However, the proportion of gastrectomies with ciliated metaplasia was $52 \%$ in Matsuyama and only $4 \%$ in New York. Thus, causes other than sex influenced the occurrence of ciliated metaplasia in the specimens.

\section{EIM and ciliated metaplasia}

In the Atlantic basin, 19\% of gastrectomies with IC (where the proportion having EIM was the highest ${ }^{24}$ ) had EIM and $9 \%$ of those also had ciliated metaplasia. In the Pacific basin, $63 \%$ of gastrectomies with IC had EIM and $45 \%$ of those had ciliated metaplasia. The difference between specimens showing EIM and ciliated metaplasia in the two basins was significant $(p<0.05)$.

\section{Number of sections/gastrectomy and ciliated metaplasia}

Table 5 shows the number of sections reviewed/gastrectomy. The mean number of sections reviewed/gastrectomy was somewhat higher in the Pacific (18.9) than in the Atlantic basin (16.5). In Stockholm, where entire gastrectomy specimens were sampled in blocks and sectioned for diagnostic and research purposes, a mean of 31.2 sections/gastrectomy was available.

The number of sections/specimen varied in the various cities. Although the mean number of sections reviewed/ specimen in Florence was only 10.9, the percent of ciliated metaplasia was relatively high (19\%). In contrast, the mean number of sections reviewed/gastrectomy in Stockholm was 31.2 sections, but only $6 \%$ of the specimens contained ciliated cells. The difference between the number of sections/ gastrectomy and the occurrence of ciliated metaplasia in the two basins was not significant $(\mathrm{p}=0.7)$.

\section{DISCUSSION}

Our comparative survey showed that gastric ciliated metaplasia was significantly more frequent in residents of the Pacific basin (mean, 29\%; range, 19-41\%) than in residents of the Atlantic basin (mean, 5\%; range, 0.5-19\%). Ciliated metaplasia was more common in specimens with IC than in those with DC, strongly suggesting that ciliated metaplasia is associated with the development of gastric neoplasia, more notably IC. 
Table 3 Ages of 105 patients with ciliated metaplasia in gastrectomy specimens dwelling at the rim of the Atlantic basin

\begin{tabular}{|c|c|c|c|c|c|c|}
\hline \multirow[b]{2}{*}{ Location } & \multicolumn{5}{|l|}{ Age } & \multirow[b]{2}{*}{ Ciliated metaplasia/patients $\geqslant 60$ years of age } \\
\hline & $\leqslant 39$ & $40-49$ & $50-59$ & $60-69$ & $\geqslant 70$ & \\
\hline New York & & 1 & 3 & 7 & 6 & $13 / 17$ \\
\hline London & & & & 3 & 4 & $7 / 7$ \\
\hline Reykjavik & 1 & 3 & 7 & 9 & 12 & $21 / 32$ \\
\hline Florence & & & 10 & 15 & 10 & $25 / 35$ \\
\hline Mexico City & & & 1 & & & $0 / 1$ \\
\hline Buenos Aires & & & & 3 & 2 & $5 / 5$ \\
\hline Boston & & & & & 1 & $1 / 1$ \\
\hline Stockholm & & & 1 & 2 & 4 & $6 / 7$ \\
\hline Total & 1 & 4 & 22 & 39 & 39 & $78 / 105$ (74\%) \\
\hline
\end{tabular}

The mean frequency of MGD specimens with ciliated metaplasia was 3\% in the Atlantic and $10 \%$ in the Pacific. Whether patients with MGD who also have ciliated metaplasia are at future risk of developing gastric carcinoma could not be answered by our study because it consisted of resected stomachs. The presence of ciliated cells in MGD indicates that the conditions that favour the transformation of native gastric cells into ciliated cells are not triggered only by the presence of a fully developed gastric tumour.

Torikata et al found ciliated cells in four of 50 cardia resections performed for oesophageal cancer. ${ }^{8}$ We found proximal ciliated metaplasia in 34\% of 573 gastrectomies performed for cardia cancer in Tokyo-Matsuyama, ${ }^{23}$ but only in $1.2 \%$ of 317 similar gastrectomies performed in New York..$^{22}$ Thus, the difference in frequency of ciliated metaplasia between the two basins also applies to patients with cardia carcinoma. Ciliated metaplasia seems to develop irrespective of the localisation of the tumour within the stomach.

The results showed that ciliated metaplasia was influenced by increasing age and by EIM, ${ }^{24}$ suggesting that ciliated cells may arise in the environment of extensive IM in the aging gastric mucosa. However, $10 \%$ and $18 \%$ of gastrectomies with IC and EIM in the Atlantic and Pacific basins, respectively, had no ciliated cells, suggesting that ciliated metaplasia might be generated through a molecular pathway different to that in EIM.

Migration within the same geographical basin did not alter the frequency of ciliated metaplasia: elderly Japanese migrants to Hawaii subsequently developing gastric carcinoma in Hawaii had a high frequency of ciliated metaplasia, similar to that seen in elderly Japanese dwelling in Japan. In contrast, populations with IC residing at similar latitudes but in different basins (Vancouver Canadians and New Yorkers in the Northern Hemisphere and those from Santiago de Chile and in Buenos Aires in the Southern Hemisphere) had different frequencies of ciliated metaplasia $(36 \%$ and $4 \%$, and $67 \%$ and $3 \%$, respectively).

This work was initiated in 1981-before the discovery of Helicobacter pylori by Warren and Marshall. ${ }^{25}$ In our subsequent studies, these bacteria were not investigated because special stains were not available at the different hospitals. Helicobacter pylori is usually absent in cases with IM because the $\mathrm{pH}$ is not optimal for the growth of these bacteria in these cases. Furthermore, the flushing of the specimens with saline after surgery (to permit the inspection of the lesion) and, in the past, the autolytic necrosis of the superficial mucosal cell layers by the intense light required for photographic documentation were detrimental to the bacteria. In retrospect, and based on the aforementioned pitfalls in the handling and processing of the resected specimens, it is assumed that the search for $H$ pylori in this survey would have led to questionable results and to unreliable conclusions. It is likely, however, that ciliated metaplasia is not triggered by $\mathrm{H}$ pylori; Mexicans, who have a high prevalence of $\mathrm{H}$ pylori, ${ }^{26}$ had the lowest frequency of ciliated metaplasia $(0.5 \%)$. "Our results show that another cellular mutation-ciliated
metaplasia-is associated with gastric carcinoma, parti-
cularly intestinal carcinoma"

It may be argued that our study has many drawbacks, namely: the size of the resected specimen varied with the topographical location of the tumour, with the size of the tumour removed, and with the technique of resection used by individual surgeons within the same hospital, between different hospitals, and between different countries. In addition, the number of blocks taken from the resected specimens by pathologists at various hospitals also varied. Despite these disadvantages, the method allowed the comparison of the state of the gastric mucosa in a considerable number of gastrectomies with carcinoma and other gastric diseases from patients dwelling in disparate geographical regions. This belief is substantiated by the fact that the detection of ciliated metaplasia was not limited by the number of sections/specimen: in the Atlantic basin, ciliated metaplasia was low (3\%) in Buenos Aires, where the mean number of sections/specimen was also low, and also in

Table 4 Ages of 411 patients with ciliated metaplasia in gastrectomy specimens dwelling at the rim of the Pacific basin

\begin{tabular}{|c|c|c|c|c|c|c|}
\hline \multirow[b]{2}{*}{ Location } & \multicolumn{5}{|l|}{ Age } & \multirow[b]{2}{*}{ Ciliated metaplasia/patients $\geqslant 60$ years of age } \\
\hline & $\leqslant 39$ & $40-49$ & $50-59$ & $60-69$ & $\geqslant 70$ & \\
\hline Tokyo-Matsuyama & & 7 & 43 & 83 & 110 & $193 / 243$ \\
\hline New Zealand & & 1 & 9 & 10 & 14 & $24 / 34$ \\
\hline Honolulu & & 2 & 6 & 19 & 39 & $58 / 66$ \\
\hline Vancouver* & & & 2 & 5 & 21 & $26 / 28$ \\
\hline Santiago & & & 1 & 12 & 27 & $39 / 40$ \\
\hline Total & & 10 & 61 & 129 & 211 & $340 / 411(83 \%)$ \\
\hline
\end{tabular}


Table 5 The mean number of sections reviewed in 3385 gastrectomy specimens seen in the Pacific $(n=1945)$ and Atlantic basins $(n=1440)$.

\begin{tabular}{llll}
\hline City in Atlantic basin & No. sections/no. cases & City in Pacific basin & No. sections/no. cases \\
\hline New York & $4452 / 627$ (7.1 sections) & Tokyo & $10787 / 469$ (23.0 sections) \\
London & $4283 / 177$ (24.2 sections) & Matsuyama & $5543 / 241$ (23.0 sections) \\
Reykjavik & $4480 / 435$ (10.3 sections) & Honolulu & $3065 / 194$ (15.8 sections) \\
Florence & $2027 / 186$ (10.9 sections) & Auckland/Otahuhu & $1557 / 175$ (8.9 sections) \\
Mexico City & $820 / 205$ (4.0 sections) & Santiago & $3288 / 120$ (27.4 sections) \\
Buenos Aires & $475 / 198$ (2.4 sections) & Vancouver & $2940 / 241$ (12.2 sections) \\
Stockholm & $3650 / 117$ (31.2 sections) & & $27180 / 1440$ (18.9 sections) \\
All cities in Atlantic basin & $20187 / 1945^{*}$ (16.5 sections) & All cities in Pacific basin & \\
\hline
\end{tabular}

Stockholm (6\%), where the mean number of sections/ gastrectomy was the highest in our present survey. In contrast, ciliated metaplasia in Santiago was high $(33 \%)$, despite the mean number of sections being lower than in Stockholm. Thus, the number of sections did not influence the detection of ciliated metaplasia in the gastrectomy specimens in our survey.

It is generally accepted that environmental carcinogens encourage the development of IM. ${ }^{27}$ With that hypothesis in mind, over an 18 year period we investigated a substantial number of resected stomachs in distant parts of the World. Because the frequency of ciliated metaplasia was lower in the Atlantic than in the Pacific basin we speculated that environmental factors acting in the Atlantic basin were either much weaker than those in the Pacific basin, or that the gastric mucosa in the Atlantic basin-for reasons unknown-was more resistant to those factors. It should be borne in mind that the Pacific basin is a higher risk zone for gastric cancer development than the Atlantic basin.

According to Correa et al, ${ }^{28}$ mutagenic-carcinogenic agent(s) present in the gastric microenvironment would trigger the sequence of cellular mutations leading to IM and to gastric carcinoma, particularly IC. We have also found that IM is associated with IC. ${ }^{24}$ Our results show that another cellular mutation-ciliated metaplasia—is associated with gastric carcinoma, particularly IC.

Snell et al postulated that nearly all mammalian cells can form cilia and that cilia are connected with cell proliferation and homeostasis. ${ }^{29}$ More recently Judd et al succeeded in eliciting gastric ciliated metaplasia in genetically manipulated

\section{Take home messages}

- We have previously reported the prevalence of ciliated cells in gastrectomies from patients dwelling in the Pacific and Atlantic basins and here we compared these results

- Ciliated metaplasia appeared to be an independent microscopic marker for the development of gastric carcinoma, and was significantly higher in the Pacific than in the Atlantic basin

- The presence of ciliated metaplasia was influenced by age and the extent of IM in both basins, but not by sex or the number of sections investigated

- Environmental carcinogens involved in the evolution of intestinal metaplasia and intestinal carcinoma seem to be implicated in gastric ciliogenesis

- Carcinogens that differ in nature and/or in strength in both basins might activate the latent natural genes encoding ciliated processes in gastric cells in patients subsequently developing gastric carcinoma, more notably of intestinal type mice. ${ }^{30}$ The studies of Judd et al may provide the opportunity to monitor, under experimental laboratory conditions, the influence of environment carcinogens on the genetic changes that unlock gastric ciliated metaplasia. ${ }^{30}$

In conclusion, our findings support the hypothesis that gastric ciliated metaplasia is an independent microscopic marker that is triggered by environmental agents. Those agents that differ in nature and/or in strength in the two basins might activate the latent natural genes that encode ciliated processes in gastric cells in patients subsequently developing gastric carcinoma, more notably of intestinal type.

Further research is necessary to disclose the environmental agents responsible for the difference in frequency of ciliated gastric cells between patients with gastric carcinoma dwelling at the rim of the two disparate oceanic basins.

\section{ACKNOWLEDGEMENTS}

We thank Professor J Rosai, former chairman of the Department of Pathology, Memorial Hospital, New York, USA; Professor J Jass, former chairman, Department of Pathology, Auckland University, Auckland, New Zealand; Dr I Filipe, former lecturer, Department of Pathology, Guy's Hospital, London, UK; and Dr G Stemmermann former chairman, Department of Pathology, Kuakini General Hospital, Honolulu, Hawaii, USA, for allowing the review of the sections of the gastrectomy specimens processed at their respective departments. This study was supported by grants from the Yamagiwa-Yoshida Foundation, Japan, The Japan Society for the Promotion of Science, the Swedish Academy of Sciences, the Swedish Society of Medicine, the Cancer Society, Stockholm, and the Karolinska Institute and Hospital, Stockholm, Sweden.

\section{Authors' affiliations}

C A Rubio, Department of Pathology, Karolinska Institute and University Hospital, Stockholm, Sweden

G Nesi, G C Zampi, Department of Pathology, Universitá Degli Studi di Firenze, Florence, Italy

P A de Ruiz, J Jessurun, Department of Pathology, Universidad Atónoma de Méjico, Mexico City, Mexico

J Jónasson, Department of Pathology, University of Iceland, 121 Reykjavik, Iceland

R Hojman, Z Kogan, Department of Pathology, Hospital Municipal de Gastroenterología, Buenos Aires, Argentina

D Antonioli, Department of Pathology, Harvard Medical School, Beth Israel Hospital, Boston, USA

M L Miller, Department of Environmental Health, University of Cincinnatti, Cincinnatti, USA

T Hirota, T Itabashi, Department of Pathology, National Cancer Center Research Institute, Tokyo 192, Japan

K Mandai, Department of Pathology, National Shikoku Cancer Center Hospital, Matsuyama, Japan

T Kitagawa, H Sugano, Y Kato, Department of Pathology, Cancer Institute, Tokyo, Japan

A King, Department of Pathology, Middlemore Hospital, Otahuhu, New Zealand

R Pisano, Department of Pathology, Hospital Jaraquemada, Santiago, Chile

D Owen, Department of Pathology, University of British Columbia, Vancouver, Canada 


\section{REFERENCES}

1 Owen D. Stomach. In: Sternberg SS, ed. Histology for pathologists, 2nd ed. Philadelphia: Lippincott-Raven, 1997:481-93.

2 Okuda T, Ogata T. An electronmicroscopic study of ciliated cells in the human gastric mucus. Arch Histol Jpn 1976;39:149-56.

3 Yamashiro K, Suzuki H, Nagayo T. Electro microscopy of ciliated cells in the human stomach. Beitr Pathol 1977;160:401-5.

4 Kato $Y$, Sugano H, Rubio CA. Classification of intramucosal cysts of the stomach. Histopathology 1983;7:931-8.

5 Stemmermann G, Hayashi T, Teruya S. The dysplastic nature of intestinal metaplasia of the stomach. In: Ming SC, ed. Precursors of gastric cancer. New York: Praeger Publishers, 1984:155-66.

6 Rubio CA, Kato Y. Ciliated metaplasia in the gastric mucosa. Studies in Japanese patients. Gann 1986;77:282-6.

7 Torikata C, Mukai M, Kawakita H. Ciliated cells in the gastric mucosa Evidence of metaplastic change. Acta Pathol Jpn 1990:40:98-106.

8 Torikata C, Mukai M. Pathology of ciliated metaplasia of the human stomach. Pathol Ann 1992;27:187-212.

9 Chan W, Hui P, Leung K, et al. Gastric adenocarcinoma with ciliated tumor cells. Hum Pathol 1993;24:1107-13.

10 Rubio CA, Kato Y, Kitagawa T, et al. Intramucosal cysts of the stomach. VIII. Histochemical studies. APMIS 1988;98:627-34.

11 Rubio CA, Hayashi T, Stemmermann G. Ciliated gastric cells: a study of thei phenotypic characteristics. Mod Pathol 1990;3:720-3.

12 Rubio CA, Hayashi T, Stemmermann G. Ciliated gastric cells among Japanese living in Hawaii. Jpn J Cancer Res 1991;82:1-4.

13 Rubio CA. Five types of pyloric cells in the antral mucosa of the stomach. Pathol Res Pract 1992;188:157-61.

14 Rubio CA, Namiki H, Stemmermann G. Further studies on geographic variation in the histological characteristics of the gastric mucosa. J Environ Pathol Toxicol Oncol 1993; 12:89-92.

15 Rubio CA, Stemmermann G. Geographic variations in the phenotype of ciliated gastric cells. J Environ Pathol Toxicol Oncol 1993; 12:93-9.

16 Rubio CA, Jass RJ, King A. Gastric cell phenotypes and intestinal metaplasia in Polynesian and non-Polynesian residents of New Zealand. J Environ Pathol Toxicol Oncol 1994; 13:243-9.
17 Rubio CA, Pisano R, Llorens $\mathrm{P}$, et al. A comparative study between the gastric mucosa of Chileans and other dwellers of the Pacific basin. Jpn J Cancer Res 1996;87:1 17-21.

18 Rubio CA, Serck-Hansen A. Ciliated metaplasia in the gastric mucosa: II in a European patient with gastric carcinoma. Pathol Res Pract 1986;181:382-4.

19 Rubio CA. Ciliated metaplasia in a gastric adenoma in a Swedish patient. APMIS 1988;96:895-7.

20 Rubio CA, Antognoli D. Ciliated metaplasia in the gastric mucosa: in an American patient. Am J Surg Pathol 1988;12:786-9.

21 Rubio CA, Jessurum P, Alonzo de Ruiz P. Geographic variations in the histologic characteristics of the gastric mucosa. Am J Clin Pathol 1991;96:330-3.

22 Rubio CA, Jonasson JG, Filipe I, et al. Gastric carcinomas of intestinal type concur with distant changes in the gastric mucosa. A multicenter study in the Atlantic basin. Anticancer Res 2001;21:813-18

23 Rubio CA, Kato Y, Yanagisawa A, et al. Cardia carinomas of intestinal type are associated with histologic changes in the gastric mucosa. Gastric Cancer 1999:2:215-30.

24 Rubio CA, Hirota T, Itabashi M, et al. Extended intestinal metaplasia. A survey of 1392 gastrectomies from dwellers of the Pacific basin. Anticancer Res 2004;24:3185-92.

25 Warren J, Marshall B. Unidentified curved bacilli on gastric epithelium in active chronic gastritis. Lancet 1983;i:1273-5.

26 Constanza CM, Eduardo LP, Javier T, et al. Determinants of Helicobacter pylori seroprevalence in Mexican adolescents. Helicobacter 2004;9:106-14

27 Correa P. Is gastric cancer preventable? Gut 2004;53:1217-19.

28 Correa P, Fontham ET, Bravo JC, et al. Chemoprevention of gastric dysplasia: randomized trial of antioxidant supplements and anti-Helicobacter pylori therapy. J Natl Cancer Inst 2000;92:1881-8.

29 Snell WJ, Pan J, Wang Q. Cilia and flagella revealed: from flagellar assembly in Chlamydomonas to human obesity disorders [review]. Cell 2004; 117:693-7.

30 Judd L, Miller ML, Andringa A, et al. Chronic gastric achlorhydria in mice lacking Atp4a produces severe hyperplasia, muco-cystic metaplasia and upregulation of growth factors, without overt carcinogenesis. J Gastroenterol Hepatol [In press.] 